\title{
Handwritten Signature
}

National Cancer Institute

\section{Source}

National Cancer Institute. Handwritten Signature. NCI Thesaurus. Code C142569.

The scripted name or legal mark of an individual written by that individual and executed or adopted with the present intention to authenticate a writing in a permanent form. (FDA) 